\title{
Urolitíase em filhote canino: Relato de caso
}

\author{
Urolitiasis in canine puppy: Case report \\ Urolitiasis en perrito: Reporte de caso
}

Recebido: 26/12/2020 | Revisado: 27/12/2020 | Aceito: 30/12/2020 | Publicado: 03/01/2021

Eugênia Tavares Barwaldt

ORCID: https://orcid.org/0000-0002-4902-1203 Universidade Federal de Pelotas, Brasil

E-mail: tbeugenia@gmail.com

Eduarda Santos Bierhals

ORCID: https://orcid.org/0000-0002-9604-8580 Universidade Federal de Pelotas, Brasil

E-mail: dudabierhals@hotmail.com

Camila Moura de Lima

ORCID: https://orcid.org/0000-0001-9306-705X Universidade Federal de Pelotas, Brasil

E-mail: camila.moura.lima@hotmail.com

Andreza Bernardi da Silva

ORCID: https://orcid.org/0000-0002-9740-5308 Universidade Federal de Pelotas, Brasil

E-mail: bernardiandreza@gmail.com

Márcia de Oliveira Nobre

ORCID: https://orcid.org/0000-0003-3284-9167 Universidade Federal de Pelotas, Brasil

E-mail: marcianobre@gmail.com

Alexsander Ferraz

ORCID: https://orcid.org/0000-0002-0424-6249

Universidade Federal de Pelotas, Brasil

E-mail: xanderferraz@yahoo.com.br

\section{Resumo}

As urolitíases são desordens de grande importância na rotina da clínica de animais de companhia, e ocorrem devido a formação de cristais, que se agregam, formando concreções sólidas denominadas urólitos. Altas concentrações de solutos, principalmente de minerais, são um dos principais fatores predisponentes para o desenvolvimento do urólito. Pode acometer ambos os sexos, mas é mais frequente nos machos com idade entre seis e onze anos. O presente relato teve como objetivo, descrever o caso de um filhote canino, castrado, diagnosticado com urolitiase. O animal apresentava sinais de disúria e anúria e na avaliação clínica, observou-se abaulamento do abdômen. Através do exame de ultrassonografia abdominal foi visualizado estruturas compatíveis com urólitos na bexiga e uretra, confirmando o diagnóstico. Para retirada dos urólitos, o procedimento realizado foi a uretrostomia escrotal. Como terapia auxiliar, foi preconizado uso de dieta calculolítica. Após um mês de tratamento dietético, foi realizada nova urinálise, onde não observou-se mais cristais, estabelecendo um bom prognóstico para o paciente.

Palavras chave: Urólito; Diagnóstico; Cães.

\begin{abstract}
Urolithiasis are disorders of great importance in the routine of the pet clinic and occur due to the formation of crystals, which aggregate, forming solid concretions called uroliths. High concentrations of solutes, mainly minerals, are one of the main predisposing factors for the development of urolith. It can affect both sexes, but it is more frequent in males aged between six and eleven years. The present report aimed to describe the case of a canine puppy, diagnosed with urolithiasis. The animal showed signs of dysuria and anuria and in the clinical evaluation, bulging of the abdomen was observed. Through abdominal ultrasound examination, structures compatible with uroliths in the bladder and urethra were visualized, confirming the diagnosis. To remove the uroliths, the procedure performed was scrotal urethrostomy. As an auxiliary therapy, the use of a calculolytic diet was recommended. After a month of dietary treatment, a new urinalysis was performed, where no more crystals were observed, establishing a good prognosis for the patient.
\end{abstract}

Keywords: Urolith; Diagnosis; Dogs.

\section{Resumen}

Las urolitiasis son trastornos de gran importancia en la rutina de la clínica de mascotas y ocurren debido a la formación de cristales, que se agregan, formando concreciones sólidas llamadas urolitos. Las altas concentraciones de solutos, especialmente minerales, son uno de los principales factores predisponentes para el desarrollo de urolitos. Puede afectar a ambos sexos, pero es más frecuente en varones de entre seis y once años. El presente informe tuvo 
como objetivo describir el caso de un perrito, diagnosticado de urolitiasis. El animal mostró signos de disuria y anuria y en la evaluación clínica se observó abombamiento del abdomen. Mediante ecografía abdominal se visualizaron estructuras compatibles con urolitos en vejiga y uretra, confirmando el diagnóstico. Para eliminar los urolitos, el procedimiento realizado fue uretrostomía escrotal. Como terapia auxiliar se recomendó el uso de dieta calculolítica. Luego de un mes de tratamiento dietético, se realizó un nuevo análisis de orina, donde no se observaron más cristales, estableciendo un buen pronóstico para el paciente.

Palabras clave: Urolito; Diagnóstico; Perros.

\section{Introdução}

As urolitíases são desordens de grande importância na clínica de animais de companhia (Koehler et al., 2008). O trato urinário dos cães e gatos possui a habilidade primordial de concentrar urina e eliminar os resíduos corporais na forma líquida (Senior e Finlayson, 1986). A supersaturação da urina com sais dissolvidos e a precipitação destes, podem levar a formação de cristais e caso não sejam excretados, podem unir-se e formar concreções sólidas denominadas urólitos.

Aproximadamente $13 \%$ das causas de afecções do trato urinário em felinos e 18\% em caninos são representadas pela urolitíase, que consiste na formação de cálculos ou urólitos, nos rins, ureter, bexiga ou uretra. Em cães, a maior incidência de cálculos encontra-se no trato urinário inferior (Fossum, 2014).

Existem fatores predisponentes para a formação de cristais e urólitos, como altas concentrações de solutos, principalmente de minerais que supersaturam a urina, junto com a diminuição na frequência de micção (Grauer, 2015). Outros fatores como a alta concentração de cristaloides na urina, a diminuição na concentração de inibidores da cristalização urinária, o pH favorável e as infecções secundárias também estão diretamente relacionados (Castro e Matera, 2005).

Em cães, a obstrução uretral ocorre frequentemente em machos e raramente em fêmeas, sendo observada com uma maior frequência em cães entre seis e onze anos de idade. As principais raças acometidas são Schnauzer miniatura, Lhasa apso, Yorkshire terrier, Bichon frisé, Shih-tzu e Poodle (Osborne et al., 1999). Os urólitos mais encontrados em cães são os de fosfato amoníaco magnesiano (estruvita) e oxalato de cálcio (Oyafuso, 2008).

O presente trabalho teve como objetivo, relatar o caso de um canino filhote, castrado, diagnosticado com urólitos de estruvita.

\section{Relato de caso}

Foi atendido em uma clínica veterinária particular no município de Pelotas/RS, um canino macho, 11 meses, castrado, sem raça definida, pesando 4,8 kg. Segundo o tutor, o animal demonstrava sinais de disúria e anúria há dois dias. Quando questionado sobre o tipo de alimentação fornecida, o mesmo informou que utilizava ração Premium para filhotes. No atendimento clínico, observou-se que o paciente encontrava-se apático e com o abdômen abaulado, sem mais alterações clínicas.

Foi realizada sondagem uretral de emergência para esvaziamento da bexiga e amenizar os sinais clínicos. Foi realizado também, ultrassonografia abdominal, onde foi possível visualizar estruturas compatíveis com urólitos na bexiga e uretra. Pelo fato do paciente continuar com quadro de anúria, foi proposta uma nova sondagem vesical de emergência, porém, a presença de uretrólitos impediram a passagem da sonda. Diante disso, foi preconizado cirurgia de emergência para retirada dos urólitos.

\section{Resultados e Discussão}

No exame de ultrassonografia abdominal, foi observado que a vesícula urinária estava distendida, com a parede espessada e superfície mucosa discretamente irregular, repleta por conteúdo anecogênico, sugestivo de cistite. Além disso, foi 
detectado no lúmen vesical, a presença de estrutura hiperecogênica arredondada, medindo aproximadamente $1 \mathrm{~cm}$ de diâmetro, confirmando a suspeita clínica de cálculo vesical (Figura 1).

Existem diversos fatores que corroboram para a formação dos urólitos, como o pH da urina, consumo reduzido de água e tipo de dieta do animal. Em caso de pH mais alcalino, há uma predisposição a formação dos cálculos de estruvita, enquanto em pH mais ácido, a formação de cálculos de oxalato de cálcio é mais frequente (Inkelmann et al., 2012).

$\mathrm{Na}$ uretra foram vistos ao menos três cálculos (Figura 2), medindo entre $0,4 \mathrm{~cm}$ e $0,8 \mathrm{~cm}$ de diâmetro, localizados no lúmen, caudais ao osso peniano, provocando a obstrução do fluxo urinário uretral. Em cães machos o local mais comum de urólitos obstrutivos é na base do osso peniano (Grauer, 2015). Nos demais órgãos, não foram presenciados nenhuma alteração.

Figura 1. Visualização de urólito em vesícula urinária através de ultrassonografia.

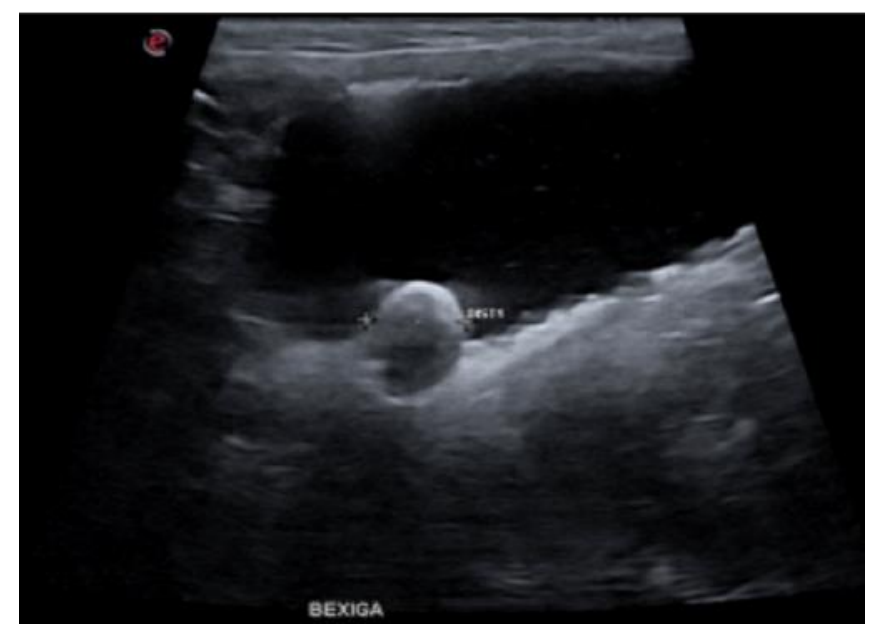

Fonte: Arquivo pessoal.

Figura 2. Identificação de três cálculos em uretra peniana através da ultrassonografia.

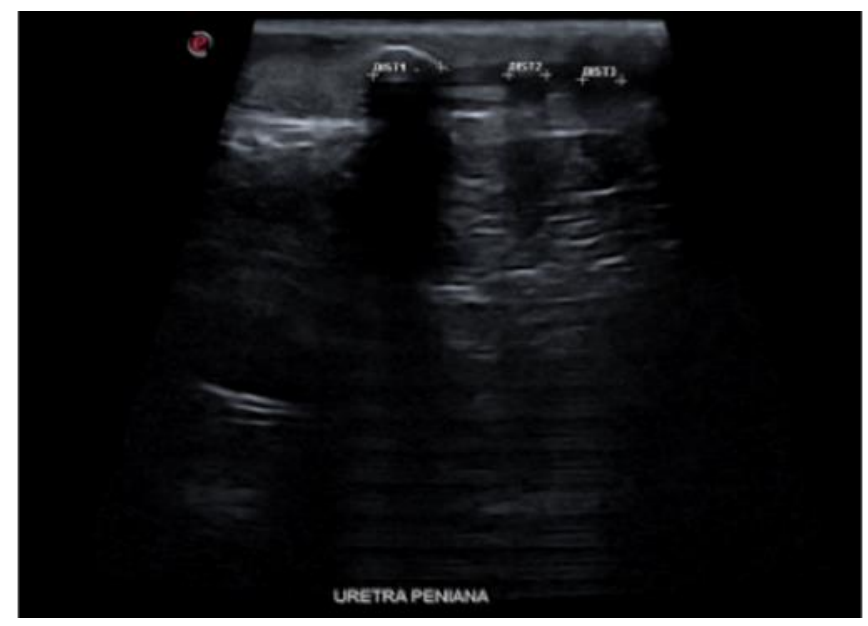

Fonte: Arquivo pessoal.

Em casos de obstrução parcial ou completa do fluxo urinário, pode ocorrer, em razão do acúmulo da urina na vesícula urinaria, quadros de cistite, hidronefrose, uremia pós-renal, e, por conseguinte, insuficiência renal aguda (Almeida et al., 2017). Devido à rápida identificação e tratamento da enfermidade, tais complicações não ocorreram com o paciente deste relato. 
Durante o procedimento cirúrgico, tentou-se realizar urohidropropulsão retrógada, a fim de deslocar os cálculos uretrais para bexiga, com o objetivo de realizar somente à cistotomia, visto que é

a uretrostomia escrotal é uma cirurgia invasiva com diversas desvantagens, como estenose uretral, possibilidade de remoção incompleta dos urólitos e a persistência da causa primária predisponente à formação de cálculos (Fossum, 2014). Porém, não foi possível devido a um dos urólitos estar preso caudal ao osso peniano. Segundo a literatura, o tratamento cirúrgico deve ser levado em consideração se o animal tiver anormalidades anatômicas, se a dissolução farmacológica não for possível, quando houver necessidade de cultura da mucosa do trato urinário ou quando os cálculos forem grandes a ponto de causar obstrução uretral (Fossum, 2014).

O paciente foi mantido internado durante três dias para cuidados pós-cirúrgicos e posterior retirada da sonda uretral, a fim de descartar estenose de uretra e observar micção. Para o tratamento pós cirúrgico, foi prescrito para analgesia, dipirona $(25 \mathrm{mg} / \mathrm{kg}$ TID) associado ao tramadol (5mg/kg TID), durante 5 dias. Foi utilizado também, anti-inflamatório, a base de meloxican $(0,05 \mathrm{mg} / \mathrm{kg}$ SID) durante 2 dias, protetor gástrico a base de omeprazol (1 $\mathrm{mg} / \mathrm{kg}$ BID) e antibioticoterapia com cefalexina (30mg/kg BID) por 7 dias. Foi recomendado ao tutor, que após o tratamento, realizasse urinálise com colheita por micção espontânea.

Na urinálise, a urina apresentava aspecto turvo e pH alcalino $(6,5)$. No exame químico, proteinúria (++) e no exame de sedimentação, cristais de oxalato de cálcio di-hidratados (++) e células vesicais (7 leucócitos/campo e 12 hemácias/campo).

Dos mais de 40 urólitos retirados cirurgicamente, 30 foram encaminhados ao laboratório LITOLAB situado em Porto Alegre/RS para análise dos núcleos separadamente a partir das suas camadas externas, já que é o método mais eficaz para avaliar a composição do urólito e posteriormente indicar qual terapia será mais efetiva (Ettinger e Feldman, 2004). Além disso, esse exame é de extrema importância posto que a causa desencadeante do urólito seja sugerida pela composição mineral de seus núcleos. Portanto, a análise quantitativa é quem irá fornecer a informação diagnóstica, prognóstica e terapêutica mais efetiva (Ettinger e Feldman, 2004).

No exame de composição do cálculo, o núcleo de crescimento não apresentava natureza específica. Todos urólitos eram de mesma espécime e o corpo compunha-se de $95 \%$ fosfato amônio magnesiano hexahidratado (estruvita), $5 \%$ fosfato de cálcio carbonatado (Carbonato-apatita) e traços de matriz orgânica amorfa. O centro do cálculo apresentava a mesma composição e a cor mais escura decorre da filtragem fotográfica (Figura 3).

Figura 3. Urólito em microscopia, medindo aproximadamente $9 \mathrm{~mm}$.

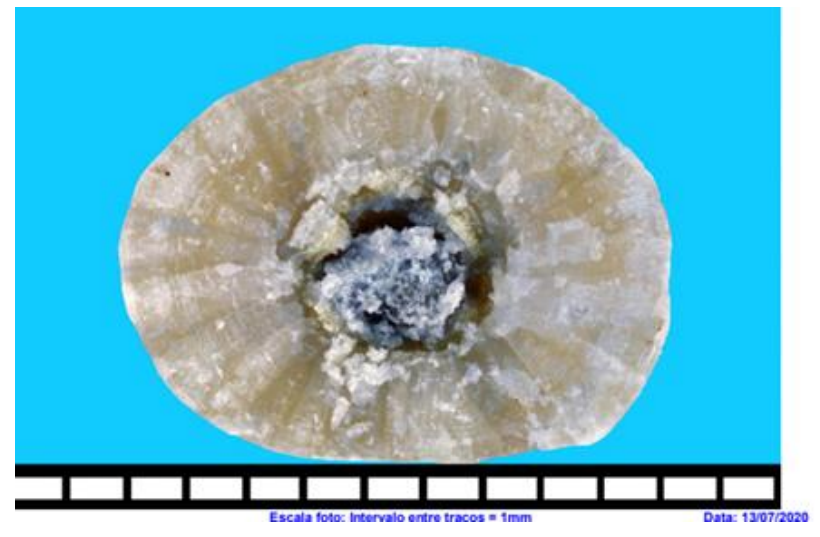

Fonte: Arquivo pessoal.

A terapia é feita de acordo com a maior composição do urólito no exame de núcleo, que é o exame padrão-ouro (Chaves et al., 2020). Porém, como as causas de cálculo não são bem elucidadas, nada descarta que o animal possa desenvolver 
cálculo com outra composição, ou ainda ser composto de vários minerais. Vale ressaltar que os urólitos são concreções policristalinas compostos primordialmente de minerais, cristaloides orgânicos e inorgânicos, e pequenas quantidades de matriz (Ariza, 2012).

Pela idade e quantidade de cálculos, é possível que o animal apresente predisposição à urolitíase. Após o resultado do exame de núcleo, foi preconizado a ração Urinary S/O da Royal Canin durante 2 meses, intercalando com uma ração super Premium. Para monitoramento da urolitiase, foi recomendado a realização mensal de urinálise para monitoramento, durante 6 meses. O manejo dietético em casos de urólitos de estruvita, por meio de dieta calculolítica específica para este cálculo, é eficiente para dissolvê-lo, entretanto, cálculos com composição cálcica não podem ser dissolvidos através da dieta. (Kaufmann et al., 2011). É importante ressaltar que o paciente submetido à dissolução clínica dos urólitos, deve ser reavaliado mensalmente através de exames como radiografia ou ultrassonografia, além de urinálises para verificar a evolução do quadro e o tamanho do urólito. Se após dois meses com tratamento clínico não houver diminuição de tamanho do urólito, deve-se considerar a remoção cirúrgica (Grauer, 2015).

Após um mês de tratamento dietético, foi realizada nova urinálise, onde não observou-se mais cristais, e a proteinúria, anteriormente presente, foi reduzida a traços, indicando resposta positiva ao tratamento e estabelecendo um bom prognóstico para o paciente.

\section{Conclusão}

A urolitíase é uma desordem recorrente do trato urinário de cães e possui diversos fatores para sua formação, principalmente nutricionais e metabólicos. O acompanhamento dos pacientes é de extrema importância para um diagnóstico precoce e para um bom prognóstico e qualidade de vida.

\section{Referências}

Ariza, P. C. Epidemiologia da urolitíase de cães e gatos. Seminário. Programa de pós-graduação em ciência animal, Universidade Federal de Goiás, Goiânia, 2012. < http://docplayer.com.br/10007241- Epidemiologia-da-urolitiase-de-caes-e-gatos.html>.

Carvalho, C. F. (2014). Ultrassonografia em pequenos animais. (2a ed.) - São Paulo: Roca, 468

Castro, P. F., \& Matera, J. M. (2005). Ureterolitíases obstrutivas em cães: avaliação da função renal na indicação da ureterotomia ou ureteronefrectomia. Revista de Educação Continuada em Medicina Veterinária e Zootecnia, 8(1):38-47.

Chaves, L. D. C. S., Silva, F. L., Sousa, J. M. C., Oliveira, J. R. A., Silva, C. R. A., Holanda, M. S., \& Santos, L. P. (2020). Urolitíase e hidrometra em cadela: relato de caso. Pubvet, 14(1):1-5.

Ettinger, S.; Feldman, E. (2004). Tratado de medicina interna veterinária: doenças do cão e do gato. Guanabara Koogan, Rio de Janeiro, 2004.

Fossum, T. W. Cirurgia de pequenos animais, (4a ed). Elsevier Brasil, São Paulo.

Grauer, G. (2015). Manifestações clínicas dos distúrbios urinários; Urolítiase canina. In: Nelson, A. W. \& Couto, C. G. (eds.) Medicina Interna de Pequenos Animais. Elsevier Editora.

Inkelmann, M. A., Kommers, G. D., Trost, M. E., Barros, C. L. S., Fighera, R. A., Irigoyen, L. F., \& Silveira, I. P. (2012). Urolitíase em 76 cães. Pesquisa Veterinária Brasileira, 32(3,):247-253.

Kaufmann, C., Neves, R. C., \& Habermann, J. C. A. (2011). Doença do trato urinário inferior dos felinos. Anuário da Produção Científica dos Cursos de PósGraduação, 4:193-214.

Koehler, L. A., Osborne, C. A., Buettner, M. T., Lulich, J. P., \& Behnke, R. (2008). Canine urolithiasis: Frequently asked questions and their answers. Veterinary Clinics of North America. Small Animal practice, 39(1):161-181.

Osborne, C. A., Sanderson, S. L., \& Lulich, J. P. (1999). Canine cystine urolithiasis: cause, detection, treatment, and prevention. Veterinary Clinics of North America: Small Animal Practice, 29, 193-211, 1999.

Oyafuso, M. K., \& Kogica, M. M. (2008). Retrospective and prospctive study of urolithiasis in dogs. São Paulo, Brasil, 146f.

Senior, D. F., \& Finlayson, B. (1986). Initiation and growth of uroliths. The Veterinary Clinics of North America: Small Animal Practice, 16(1):19-26. 